\title{
Biomarkers, shock index and modified early warning score among older medical hospital inpatients in Nigeria
}

\author{
LA Adebusoye ${ }^{a *}$, MO Owolabi ${ }^{b}$ and A Ogunniyi ${ }^{b}$ \\ ${ }^{a}$ Chief Tony Anenih Geriatric Centre (CTAGC), University College Hospital, Ibadan, Nigeria \\ ${ }^{b}$ Department of Medicine, College of Medicine, University of Ibadan, Ibadan, Nigeria \\ *Corresponding author, email: larrymacsoye@yahoo.com
}

Background: Biomarkers, shock index and modified early warning score (MEWS) are of public health importance because identification and prompt attention to them have been found to reduce mortality among older patients on admission. Objectives: A study was undertaken to determine the biomarkers, shock index and MEWS that predict mortality on admission among older medical hospital inpatients.

Methods: This was a prospective study of 450 patients ( $\geq 60$ years) on the medical wards of University College Hospital, Ibadan. Biomarkers recommended by the National Institute on Aging such as blood pressure, heart rate and pulse rate (cardiovascular functioning); cholesterol and triglycerides (metabolic processes); T-cell counts (immune system status) and weight, body mass index and waist-to-hip ratio (indicators of obesity, chronic metabolic disorders and fat deposits) were assessed. Vital signs were recorded on admission and used to calculate the shock index and MEWS. Multivariate and survival analyses were carried out at $p<0.05$.

Results: Baseline temperature $\geq 39.0^{\circ} \mathrm{C}(p=0.049)$, pulse rate $\geq 100$ beats/minute $(p=0.034)$, systolic blood pressure (SBP) < $120 \mathrm{mmHg}(p=0.048)$, shock index $\geq 1.0(p=0.041)$, age shock index $(p=0.032)$ and critical illness score (MEWS $\geq 5)$ $p=0.019$ were significantly associated with mortality. Independent predictors of mortality on Cox regression analysis were temperature $\geq 39.0^{\circ} \mathrm{C}(\mathrm{HR}=3.317$ [1.281-8.590]) and $\mathrm{SBP}<120 \mathrm{mmHg}(\mathrm{HR}=1.845$ [1.025-3.322]).

Conclusion: Prompt identification and management of fever and low blood pressure should improve the survival of older medical hospital inpatients.

Keywords: Biomarkers, MEWS, Nigeria, older patients, shock index

\section{Introduction}

Biomarkers are biological indicators that serve as predictors of disease (illness) and mortality. ${ }^{1-3}$ Many authors and researchbased groups have proposed different biomarkers, which singly or in combination could predict mortality. ${ }^{1-4}$ However, none has been found to fully predict mortality in older patients due to the intrinsic multi-causal and multi-system nature of the ageing process. ${ }^{3}$ In low- and medium-income countries (LMICs) such as Nigeria, sophisticated biomarkers such as the indicators of genotype, pathogenic processes and pharmacological responses to therapeutic interventions are not readily available because of cost and technology constraints. ${ }^{5}$ Hence, the reliance on biomarkers, which are relatively easy to measure and are often part of routine medical examinations. In Africa, the South African Study on Global Ageing (SA SAGE) used biomarkers that measure anthropometry, performance tests and routine blood analysis (haemoglobin, glycated haemoglobin and HIV status) among the community-dwelling elderly to assess their health status..$^{5}$ While in Nigeria, cardio-metabolic biomarkers such as blood pressure, triglycerides, high-density lipoprotein, low-density lipoprotein and C-reactive protein were used to determine the risk of mortality associated with obesity among the older Yoruba and African Americans. ${ }^{6}$ The above studies have shown the importance of routine measurement of biomarkers in older Africans.

The National Institute on Aging (NIA) grouped the relevant biomarkers of mortality in older persons into four processes, namely cardiovascular functioning; metabolic processes; indicators of obesity, chronic metabolic disorders and fatty deposits; and immune system status. ${ }^{1}$ The addition of these risk indicators could create an index which captures higher health risks occasioned by biological processes that occur simultaneously in a hospitalised older individual. ${ }^{1}$

Early warning scores are easy to measure derivatives of physiological parameters such as vital signs (systolic blood pressure, heart rate, respiratory rate and temperature) and the level of consciousness. ${ }^{7}$ Early warning scores are useful in identifying critically ill older hospital inpatients on medical admission. Subbe et al. and Kruisselbrink et al. validated the modified version (MEWS) and derived a score of $\geq 5$ for critically ill patients (OR $=5.4$ for in-hospital mortality). ${ }^{7,8}$ The MEWS facilitates early intervention and prompt management, in addition to predicting mortality among older patients.

The shock index (SI) has been found useful in predicting mortality in acutely ill patients as it was found to be superior to systolic blood pressure (SBP) and heart rate (HR) alone. ${ }^{9,10}$ Other indices have been developed by investigators to predict mortality, especially in acutely ill older patients. These include the age shock index (age SI) and the modified shock index (MSI), which have been found to be better predictors of mortality than SI, HR and SBP in hospitalised older patients. ${ }^{9,10}$

Geriatric medicine is just evolving in Nigeria and, to our knowledge, this was the first prospective study to look at the biomarkers, shock index and MEWS among hospitalised older patients admitted to the medical wards of a tertiary hospital in Nigeria. Physiologic parameters are often incorrectly measured, 
documented and seldom addressed by healthcare workers in Nigeria due to lack of awareness and poor understanding of their importance to the survival of older hospital inpatients. We used biomarkers suggested by the NIA because of their availability, affordability and relevance at the primary, secondary and tertiary tiers of the healthcare sector in Nigeria. This study aimed to identify biomarkers, shock index and MEWS, which predict mortality among hospitalised older patients on admission.

\section{Methods}

This prospective observational study was conducted between May 2013 and November 2014 on mortality among hospitalised older patients. University College Hospital (UCH), Ibadan, which is a 1000 -bedded hospital, was the study site. Ibadan is the metropolitan capital of Oyo state in the south-western part of Nigeria. There are 150 beds in the six medical wards of $\mathrm{UCH}$, which cover major specialities in medicine, namely Neurology, Cardiology, Nephrology, Gastroenterology, Pulmonology, Infectious Diseases, Dermatology and Endocrinology. Older patients are admitted into the medical wards based on their diagnoses and the body system involved.

Older patients aged 60 years and above who were admitted consecutively to the medical wards of UCH during the study period were recruited. Their ages were determined by direct recall and the use of historical events for those who could not recall their ages. ${ }^{11,12}$ All non-consenting older patients were excluded. The Leslie Kish formula for single proportion was employed in calculating the sample size of 450 patients using the best estimate for mortality among older medical hospital inpatients in Nigeria. ${ }^{13}$

A pre-tested, interviewer-administered, semi-structured questionnaire that included clinical evaluation and laboratory tests was used by the medical team, which comprised resident doctors, nurses and a trained research assistant, to obtain data from the respondents. Predetermined biomarkers of mortality, which included cardiovascular functioning (systolic and diastolic blood pressure, heart rate and pulse rate), metabolic processes (cholesterol, lipoproteins and triglycerides), indicators of obesity, chronic metabolic disorders and fatty deposits (body measurements such as weight, body mass index and waist-to-hip ratio) and immune system status (white cell counts) were obtained on admission. ${ }^{1}$ Similarly, the level of consciousness, daily temperature and respiratory rate were also recorded on admission.

The systolic and diastolic blood pressures were measured with an Accoson mercury sphygmomanometer ${ }^{\circledR}$ (AC Cossor \& Son Surgical, Harlow, UK), which had been calibrated and validated before use. After 5 minutes' rest, appropriate cuff sizes were used for each respondent, encircling at least $80 \%$ of the upper arm. Two separate readings, two minutes apart, were averaged for the reported blood pressure measurement. ${ }^{14} \mathrm{~A}$ stadiometer manufactured by Seca Corporation (Hanover, USA) was used to measure height to the nearest 0.1 metre. Weight was measured with a weighing scale manufactured by Hana (Shenzhen, China) to the nearest $0.1 \mathrm{~kg}$. The zero mark on the scale was checked for accuracy after every reading. Waist and hip circumferences were measured to the nearest $0.1 \mathrm{~cm}$, using a flexible, non-elastic measuring tape.

The $\mathrm{SI}$ is a measure of haemodynamic stability, which is calculated as heart rate (HR) divided by systolic blood pressure (SBP). ${ }^{8,9}$ The MSI is the ratio of the heart rate to the mean blood pressure while the age $\mathrm{SI}$ is the $\mathrm{SI}$ multiplied by age. ${ }^{8,9}$
The SI, MSI and age SI were calculated using vital signs on admission. The cut-off scores for each measure were defined based on the previous study. ${ }^{10}$ Haemodynamic instability was defined as an $\mathrm{SI}$ equal to or greater than 1, an MSI equal to or greater than 1.3 , and an age SI equal to or greater than $50 .{ }^{10}$

The modified early warning score (MEWS) was derived from the respondents' systolic blood pressure, respiratory rate, heart rate, temperature and level of consciousnessaon admission (Supplementary Table). ${ }^{7}$ Using the previously published criteria, each component was scored and the 'critical score' was taken as a score of 5 or more. ${ }^{7}$ MEWS is a widely applied physiological scoring system that assists with the identification of patients at risk of catastrophic deterioration during hospitalisation. ${ }^{7}$

The Statistical Package for the Social Sciences (SPSS) version 20 (IBM Corp, Armonk, NY, USA) was used for data entry, cleaning and analysis. Descriptive statistics were used to describe the sociodemographic characteristics of the respondents. Student's $t$-test was used to test the association between continuous variables. Median survival times (MSTs) of hospitalisation for all the respondents (from admission to death or discharge) were compared using the Kaplan-Meier (K-M) method. Log-rank (Mantel-Cox) test was carried out to test the null hypothesis. Cox proportional hazard regression analysis was carried out to determine the predictors of all-cause mortality using the variables that showed significant association with all-cause mortality on log-rank (MantelCox) test. The $p$-value of significance was set at $p \leq 0.05$.

Ethical approval for the study was obtained from the University of Ibadan/University College Hospital Institutional Ethical Review Board (UI/EC/12/0092). Informed consent was obtained from each respondent before administration of the questionnaire.

\section{Results}

There were 234 (52.0\%) females and $216(48.0 \%)$ males in the study population. The mean age of the respondents was $71.5 \pm$ 8.0 years (females $=71.7 \pm 8.1$ years $>$ males $=71.2 \pm 7.9$ years; $p=0.55)$. The majority of the respondents $(309 ; 68.7 \%)$ were still married and had formal education (76.4\%). There were $99(22.0 \%)$ deaths $($ male $=60[27.8 \%]>$ female $=39[16.7 \%]$; $p=0.004)$.

\section{Biomarkers}

Table 1 gives the mean values of the biomarkers by the outcomes of hospitalisation on admission. Respondents who died on hospital admission had a higher LDL/HDL ratio $(p=0.019)$ compared with those who were discharged.

The respondents' vital signs on admission were dichotomised using appropriate cut-off values. The MSTs were significantly lower among respondents who had temperature $\geq 39.0^{\circ} \mathrm{C}$ $(p=0.049)$, pulse rate $\geq 100 \mathrm{bpm}(p=0.034)$ and systolic blood pressure $<120 \mathrm{mmHg}(p=0.048$, Table 2$)$.

\section{Shock index}

The MSTs of hospitalisation by the SI, MSI and age SI on admission are shown in Table 3 and Figure 1 (a)-(c). The proportions of mortality among respondents who had $\mathrm{SI} \geq 1.0$, age $\mathrm{SI} \geq 50$ and MSI $\geq 1.3$ were $35.5 \%, 25.8 \%$ and $41.7 \%$ respectively. Respondents who had $\mathrm{SI} \geq 1.0$ and age $\mathrm{SI} \geq 50$ had significantly shorter MSTs than those who had $\mathrm{SI}<1.0$ and age $\mathrm{SI}<50$ ( $p=0.041$ and $p=0.032$ respectively). The MST of respondents who had MSI $\geq 1.3$ was shorter than those who had MSI $<1.3$, without any statistical difference $(p=0.344)$. 
Table 1: Mean values of biomarkers by outcomes of hospitalisation on admission

\begin{tabular}{|c|c|c|c|c|}
\hline Variables & $\begin{array}{l}\text { Dead }=99 \\
\text { Mean } \pm S D\end{array}$ & $\begin{array}{c}\text { Discharged }=351 \\
\text { Mean } \pm \text { SD }\end{array}$ & $t$-test value & $p$-value \\
\hline \multicolumn{5}{|l|}{ Cardiovascular functioning $(n=450)$ : } \\
\hline Temperature $\left({ }^{\circ} \mathrm{C}\right)$ & $36.9 \pm 0.6$ & $36.8 \pm 0.5$ & 0.664 & 0.509 \\
\hline Systolic blood pressure $(\mathrm{mmHg})$ & $141.5 \pm 42.0$ & $164.8 \pm 44.2$ & -0.502 & 0.618 \\
\hline Diastolic blood pressure (mmHg) & $81.8 \pm 10.6$ & $84.0 \pm 10.9$ & -1.663 & 0.411 \\
\hline Respiratory rate (cycles/min) & $27.6 \pm 8.2$ & $28.4 \pm 11.8$ & -0.357 & 0.723 \\
\hline Pulse rate (beats/min) & $93.3 \pm 11.3$ & $91.9 \pm 10.1$ & 1.181 & 0.242 \\
\hline $\mathrm{SpO} 2(\%)$ & $95.8 \pm 3.6$ & $95.9 \pm 3.5$ & -0.339 & 0.741 \\
\hline \multicolumn{5}{|c|}{ Body measurements/indicators of obesity $(n=424)$ : } \\
\hline Weight (kg) & $72.3 \pm 11.9$ & $71.4 \pm 10.8$ & 0.629 & 0.530 \\
\hline Height (cm) & $165.3 \pm 7.5$ & $163.4 \pm 7.8$ & 1.986 & $0.048^{*}$ \\
\hline Waist circumference $(\mathrm{cm})$ & $94.0 \pm 16.3$ & $94.9 \pm 6.9$ & -0.442 & 0.659 \\
\hline Hip circumference $(\mathrm{cm})$ & $97.9 \pm 11.8$ & $99.0 \pm 12.2$ & -0.717 & 0.474 \\
\hline Waist-hip ratio (WHR) & $0.959 \pm 0.1$ & $0.962 \pm 0.2$ & -0.126 & 0.900 \\
\hline Body mass index $\left(\mathrm{kg} / \mathrm{m}^{2}\right)$ & $26.6 \pm 5.1$ & $26.9 \pm 5.1$ & -0.379 & 0.705 \\
\hline \multicolumn{5}{|l|}{ Metabolic processes $(n=389)$ : } \\
\hline Total cholesterol (g/dl) & $186.8 \pm 48.6$ & $178.4 \pm 46.6$ & 1.142 & 0.254 \\
\hline $\mathrm{HDL}(\mathrm{g} / \mathrm{dl})$ & $46.5 \pm 16.2$ & $50.1 \pm 18.1$ & -1.410 & 0.160 \\
\hline LDL (g/dl) & $106.2 \pm 29.7$ & $98.0 \pm 27.2$ & 1.831 & 0.068 \\
\hline LDL/HDL ratio & $2.4 \pm 0.8$ & $2.2 \pm 0.7$ & 2.353 & $0.019^{*}$ \\
\hline TGA (g/dl) & $119.1 \pm 45.2$ & $114.5 \pm 36.3$ & 0.687 & 0.493 \\
\hline \multicolumn{5}{|c|}{ Immune status and other haematological processes $(n=393)$ : } \\
\hline WBC (/mm3) & $16377 \pm 41251$ & $11351 \pm 7923$ & 1.020 & 0.308 \\
\hline PCV (\%) & $32.6 \pm 7.8$ & $33.9 \pm 9.3$ & -1.161 & 0.249 \\
\hline Platelets (/litre) & $248366 \pm 137410$ & $255178 \pm 147442$ & -0.349 & 0.727 \\
\hline
\end{tabular}

*Significant at $5 \%$ level of significance.

\section{Modified early warning score (MEWS)}

The overall MEWS was $3.54 \pm 1.84$ (range 1-12). Respondents who died had higher MEWS compared with those who were discharged $(3.82 \pm 1.79$ vs. $3.46 \pm 1.84, p=0.117)$. A total of 115 (29.3\%) respondents had a critical illness score (MEWS $\geq 5$ ). Significantly, a higher proportion of respondents with critical illness score (MEWS $\geq 5$ ) died following hospital admission (39.8\%) compared with those who were discharged (26.5\%), $p=0.019$.

Temperature $\geq 39.0^{\circ} \mathrm{C}(\mathrm{HR}=3.317 ; 95 \% \mathrm{Cl}=1.281-8.590, p=$ $0.008)$ and systolic blood pressure $<120 \mathrm{mmHg}(\mathrm{HR}=1.845$; $95 \% \mathrm{Cl}=1.025-3.322, p=0.042)$ were the independent predictors of all-cause mortality (Table 4$)$.

\section{Discussion}

The association between biomarkers and all-cause mortality among older hospital inpatients on admission had been reported in the literature with the development of hundreds of biomarkers. ${ }^{2}$ Clinical applications of biomarkers generally include prognosticating for individual older patients, identifying high-risk older patients during hospitalisation and helping healthcare workers decide on the best treatment options. ${ }^{15,16}$ In this study, we found low systolic blood pressure (SBP < $120 \mathrm{mmHg})$ and elevated temperature $\left(\geq 39.0^{\circ} \mathrm{C}\right)$ to be the independent predictors of all-cause mortality among older medical hospital inpatients.

As in previous studies ${ }^{18-20}$ an SBP of less than $120 \mathrm{mmHg}$ was a predictor of mortality. SBP has been found to be a more important and predictive measure of ageing health outcomes compared with diastolic blood pressure (DBP). ${ }^{16} \mathrm{~A}$ similar study by
Morrisey et al. reported a mortality HR $>2.3$ for low SBP. ${ }^{17}$ This is not surprising as cardiovascular insufficiency is one of the leading causes of disability and death in the older population. ${ }^{16}$ Similarly, a study reported that a third of stable older patients with 'normal blood pressures' (SBP of $90-140$ and DBP of 60$90 \mathrm{mmHg}$ ) died within 24 hours of admission due to a cardiac arrest resulting from hypoperfusion. ${ }^{18}$ This has called for the redefinition of hypotension in older patients during an acute emergency. Oyetunji et al. and Eastridge et al. proposed an SBP cut-off of $117 \mathrm{mmHg}$ and $110 \mathrm{mmHg}$ respectively for hypotension in older patients. ${ }^{18,19}$ Though these studies were among older trauma patients, the redefined cut-offs could also be used for older patients in an acute stressful situation, especially during medical admission. ${ }^{18,19}$ Older patients are mostly hospitalised due to the acute exacerbation and complications of their chronic medical illnesses and they experience diminished cardiac output and poor functional capacity during the period of hospitalisation against a background of age-related increased peripheral vascular resistance. ${ }^{18,20}$

Temperature is an important biomarker of illness severity and pyrexia is an independent predictor of mortality in critically ill patients. ${ }^{21}$ Elevated temperature $\left(\geq 39.0^{\circ} \mathrm{C}\right)$ was a predictor of mortality in our study with an HR of 3.3 , which was similar to the reports in other studies. ${ }^{21,22}$ Many controversies surround the degrees at which fever should be treated in older patients, as only a few studies have established a normal body temperature for older patients. ${ }^{23}$ It is generally agreed that close monitoring and regulation of extremely elevated body temperature is important in the critically ill patient as this will prevent the uncontrolled disruption of homeostasis and subsequent organ dysfunction and failure. ${ }^{22,24}$ 
Table 2: Median survival times of hospitalisation by vital signs on admission

\begin{tabular}{|c|c|c|c|c|c|c|}
\hline Variables & $\begin{array}{l}\text { Number of } \\
\text { respondents }\end{array}$ & $\begin{array}{c}\text { Number of } \\
\text { deaths } \\
n(\%)\end{array}$ & $\begin{array}{c}\mathrm{MST} \pm \mathrm{SE} \\
\text { (days) }\end{array}$ & $95 \% \mathrm{Cl}$ of MST (days) & $\begin{array}{l}\text { Log rank (Mantel- } \\
\text { Cox) } \\
\text { chi-square }\end{array}$ & $p$-value \\
\hline \multicolumn{7}{|c|}{ Temperature $\left({ }^{\circ} \mathrm{C}\right)$ : } \\
\hline$<39.0$ & 436 & $93(21.3)$ & $36.0 \pm 2.6$ & $30.8-41.1$ & 3.866 & $0.049^{*}$ \\
\hline$\geq 39.0$ & 14 & $6(42.9)$ & $17.0 \pm 5.1$ & $7.0-27.0$ & & \\
\hline \multicolumn{7}{|c|}{ Pulse rate (beats per minute): } \\
\hline$<100$ & 326 & $64(19.6)$ & $40.0 \pm 3.5$ & $33.2-46.8$ & 4.493 & $0.034^{*}$ \\
\hline$\geq 100$ & 124 & $35(28.2)$ & $30.0 \pm 4.2$ & $21.7-38.6$ & & \\
\hline \multicolumn{7}{|c|}{ Systolic blood pressure $(\mathrm{mmHg})$ : } \\
\hline$<120$ & 118 & $32(27.1)$ & $29.0 \pm 4.4$ & $26.2-31.8$ & 3.901 & $0.048^{*}$ \\
\hline$\geq 120$ & 332 & $67(20.2)$ & $40.0 \pm 2.9$ & $34.8-45.2$ & & \\
\hline \multicolumn{7}{|c|}{ Diastolic blood pressure $(\mathrm{mmHg})$ : } \\
\hline$<60$ & 56 & $14(25.0)$ & $36.0 \pm 3.2$ & $29.7-42.3$ & 0.186 & 0.666 \\
\hline$\geq 60$ & 394 & $85(21.6)$ & $40.0 \pm 4.2$ & $31.8-48.2$ & & \\
\hline \multicolumn{7}{|c|}{ Respiratory rate (cycles per minute) } \\
\hline$\geq 25$ & 242 & $59(24.4)$ & $36.0 \pm 3.0$ & $30.1-41.9$ & 0.143 & 0.706 \\
\hline$<25$ & 208 & 40 (19.2) & $40.0 \pm 6.4$ & $27.4-52.6$ & & \\
\hline
\end{tabular}

*Significant at $5 \%$ level of significance.

Table 3: Median survival times of hospitalisation by SI, MSI and age SI on admission

\begin{tabular}{|c|c|c|c|c|c|c|}
\hline Variables & $\begin{array}{l}\text { Number of } \\
\text { respondents }\end{array}$ & $\begin{array}{c}\text { Number of } \\
\text { deaths } \\
n(\%)\end{array}$ & $\begin{array}{c}\text { MST } \pm \text { SE } \\
\text { (days) }\end{array}$ & $95 \% \mathrm{Cl}$ of MST (days) & $\begin{array}{c}\text { Log rank (Mantel- } \\
\text { Cox) } \\
\text { chi-square }\end{array}$ & $p$-value \\
\hline \multicolumn{7}{|c|}{ Shock index (SI): } \\
\hline$<1.0$ & 419 & $88(21.0)$ & $40.0 \pm 2.4$ & $35.3-44.7$ & 4.156 & $0.041^{*}$ \\
\hline$\geq 1.0$ & 31 & $11(35.5)$ & $30.0 \pm 13.2$ & $4.0-55.9$ & & \\
\hline \multicolumn{7}{|c|}{ Age shock index (Age SI): } \\
\hline$<50$ & 268 & $52(19.4)$ & $40.0 \pm 4.5$ & $31.6-48.8$ & 4.753 & $0.029^{*}$ \\
\hline$\geq 50$ & 182 & $47(25.8)$ & $30.0 \pm 3.3$ & $23.6-36.4$ & & \\
\hline \multicolumn{7}{|c|}{ Modified shock index (MSI): } \\
\hline$<1.3$ & 438 & $94(21.5)$ & $36.0 \pm 2.2$ & $31.6-40.4$ & 0.894 & 0.344 \\
\hline$\geq 1.3$ & 12 & $5(41.7)$ & $30.0 \pm 14.6$ & $13.8-58.6$ & & \\
\hline
\end{tabular}

*Significant at $5 \%$ level of significance.

We found a significant association between the shock index (SI) and mortality, in agreement with previous studies. However, SI was not an independent predictor of mortality in this study. Shock index is an effective predictor of short-term mortality, hence its importance among medical older hospital inpatients on admission, though its predictive power for long-term mortality is controversial. ${ }^{10}$ Also, the MEWS identified $29.3 \%$ of the respondents as being critically ill with mortality in $39.8 \%$ of them. MEWS has been regarded as a defined judgement on routinely recorded physiological data. ${ }^{7}$ It was therefore not surprising that a critical score (MEWS $\geq 5$ ) was significantly associated with mortality in our study.
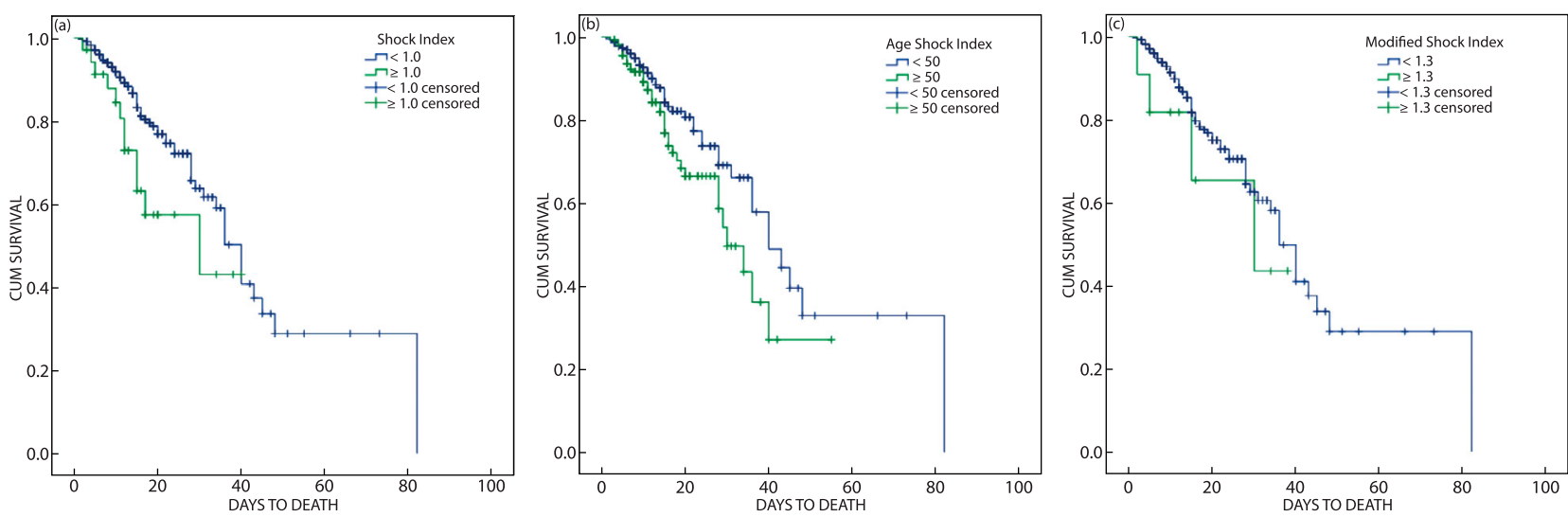

Figure 1: (a) The survival function of hospitalisation by shock index; (b) The survival function of hospitalisation by age shock index (age Sl); (c) The survival function of hospitalisation by modified shock index (MSI). 
Table 4: Multiple Cox regression model of all-cause mortality and biomarkers

\begin{tabular}{lccc}
\hline Factor & B & $\boldsymbol{p}$-value & $\begin{array}{c}\text { Hazard ratio } \\
(95 \% \mathrm{Cl})\end{array}$ \\
\hline Temperature $\left(\geq 39.0^{\circ} \mathrm{C}\right)$ & 1.199 & $0.008^{*}$ & $3.317(1.281-8.590)$ \\
Pulse rate $(\geq 100 \mathrm{bpm})$ & 0.385 & 0.151 & $1.469(0.865-2.496)$ \\
$\begin{array}{l}\text { Systolic blood pressure }(< \\
120 \mathrm{mmHg})\end{array}$ & 0.612 & $0.042^{*}$ & $1.845(1.025-3.322)$ \\
Shock index $(\geq 1.0)$ & 0.357 & 0.434 & $1.429(0.589-3.472)$ \\
Age SI $(\geq 50)$ & 0.245 & 0.379 & $1.278(0.740-2.208)$ \\
\hline
\end{tabular}

*Significant at $5 \%$ level of significance.

\section{Strengths and limitations}

The prospective cohort design and the inclusion of all major specialities in medicine were the major strengths of this study. Its limitation was that the laboratory tests were not completed for all the respondents.

\section{Conclusion}

This study has highlighted the use of vital signs to identify abnormal pathophysiologic states and to monitor outcomes of hospitalisation among older patients in the medical wards of a lowand medium-income country. SBP and temperature are important biomarkers of mortality, which should not only be routinely measured but any abnormality should be promptly addressed by healthcare workers on medical admission of older persons. The finding of low SBP as a predictor of mortality calls for the redefinition of SBP among acutely ill older Nigerians as a matter of public health importance. The high mortality recorded among critically ill older patients calls for the routine calculation of MEWS on admission, closer monitoring and prompt intervention to improve survival among older medical hospital inpatients.

Disclosure statement - No potential conflict of interest was reported by the authors.

Supplemental data - Supplemental data for this article can be accessed here https://doi.org/10.1080/20786190.2018.1554304.

\section{References}

1. PRB. Use of biomarkers in predicting health and mortality. Today's Research on Aging. 2008;(14):1-6.

2. Lara J, Cooper R, Nissan J, et al. A proposed panel of biomarkers of healthy ageing. BMC Med. 2015;13(1):222. http://doi.org/10.1186/ s12916-015-0470-9

3. Bürkle A, Moreno-Villanueva M, Bernhard J, et al. MARK-AGE biomarkers of ageing. Mech Ageing Dev. 2015;151:2-12. http://doi. org/10.1016/j.mad.2015.03.006

4. Zhang WG, Zhu SY, Bai XJ, et al. Select aging biomarkers based on telomere length and chronological age to build a biological age equation. Age (Omaha). 2014;36(3):1201-11. http://doi.org/10.1007/ s11357-014-9639-y

5. WHO SAGE WAVE 1. The Study on global AGEing and adult health (SAGE) [Internet]. South Africa. 2010. Available from: www.who.int/ healthinfo/systems/ sage/en/index.html

6. Clark DO, Gao S, Lane KA, et al. Obesity and 10-year mortality in very old african Americans and yoruba-Nigerians: exploring the obesity paradox. J Gerontol A Biol Sci Med Sci. 2014;69(9):1162-9. Available from: http://www.ncbi.nlm.nih.gov/pubmed/24694355. http://doi. org/10.1093/gerona/glu035

7. Subbe $C P$, Kruger $M$, Rutherford $P$, et al. Validation of a modified early warning score in medical admissions. QJM. 2001;94(10):521-6. http:// doi.org/10.1093/qjmed/94.10.521
8. Kruisselbrink R, Kwizera A, Crowther M, et al. Modified early warning score (MEWS) identifies critical illness among ward patients in a resource restricted setting in Kampala, Uganda: A prospective observational study. PLoS One. 2016;11(3):e0151408. http://doi.org/10. 1371/journal.pone.0151408

9. Sankaran P, Kamath AV, Tariq SM, et al. Are shock index and adjusted shock index useful in predicting mortality and length of stay in community-acquired pneumonia? Eur J Intern Med. 2011;22(3):282-5. Available from: http://www.ncbi.nlm.nih.gov/pubmed/21570648. http://doi.org/10.1016/j.jim.2010.12.009

10. Kim SY, Hong KJ, Shin SD, et al. Validation of the shock index, modified shock index, and age shock index for predicting mortality of geriatric trauma patients in emergency departments. J Korean Med Sci. 2016;31(12):2026-32. http://doi.org/10.3346/jkms.2016.31.12.2026

11. Paraïso MN, Houinato $D$, Guerchet $M$, et al. Validation of the use of historical events to estimate the age of subjects aged 65 years and over in Cotonou (Benin). Neuroepidemiology. 2010;35(1):12-6. Available from: http://www.ncbi.nlm.nih.gov/pubmed/20339306. http://doi.org/10.1159/000301715

12. Ogunniyi A, Osuntokun BO. Determination of ages of elderly Nigerians through historical events: validation of ajayi-igun 1963 listing. West Afr J Med. 1993;12(4):189-90. Available from: http:// www.ncbi.nlm.nih.gov/pubmed/8199057

13. Sanya EO, Akande TM, Opadijo G, et al. Pattern and outcome of medical admission of elderly patients seen at university of llorin teaching hospital, llorin. African J Med Med Sci. 2008;37(4):375-81.

14. World Health Organization/ International Society of Hypertension Writing Group. 2003 world health organization (WHO)/international society of hypertension (ISH) statement on management of hypertension. J Hypertens. 2003; 21(11):1983-92. http://doi.org/10.1097/ 00004872-200311000-00002

15. Peto MV, De la Guardia C, Winslow K, et al. Mortalitypredictors. org : a manually - curated database of published biomarkers of human all cause mortality. Aging (Albany NY). 2017;9(8):1916-25. https://doi. org/10.18632/aging.101280

16. Crimmins E1, Vasunilashorn S, Kim JK, et al. Biomarkers related to aging in human populations. Adv Clin Chem. 2008;46:161-216. http://doi.org/10.1016/S0065-2423(08)00405-8

17. Morrissey Y, Bedford M, Irving J, et al. Older people remain on blood pressure agents despite being hypotensive resulting in increased mortality and hospital admission. Age Ageing. 2016;45(6):783-8. Available from: https://academic.oup.com/ageing/article-lookup/ doi/10.1093/ageing/afw120. http://doi.org/10.1093/ageing/afw120

18. Oyetunji TA, Chang DC, Crompton JG, et al. Redefining hypotension in the elderly: normotension is not reassuring. Arch Surg. 2011;146 (7):865-9. Available from: http://www.ncbi.nlm.nih.gov/pubmed/ 21768435. http://doi.org/10.1001/archsurg.2011.154

19. Eastridge BJ, Salinas J, McManus JG, et al. Hypotension begins at $110 \mathrm{~mm}$ Hg: redefining 'hypotension' with data. J Trauma. 2007;63 (2):291-7; discussion 297-9. Available from: http://www.ncbi.nlm. nih.gov/pubmed/17693826. http://doi.org/10.1097/TA. 0b013e31809ed924

20. Adebusoye L, Owolabi M, Kalula S, et al. All-cause mortality among elderly patients admitted to the medical wards of hospitals in Africa: A systematic review. Niger J Heal Sci. 2015;15(1):45-51. Available from: http://www.chs-journal.com/text.asp?2015/15/1/45/ 171372. http://doi.org/10.4103/1596-4078.171372

21. Faulds $M$, Meekings $T$. Temperature management in critically ill patients. Contin Educ Anaesthesia, Crit Care Pain. 2013;13(3):75-9. http://doi.org/10.1093/bjaceaccp/mks063

22. Gozzoli V, Schöttker P, Suter PM, et al. Is it worth treating fever in intensive care unit patients? preliminary results from a randomized trial of the effect of external cooling. Arch Intern Med. 2001;161 (1):121-3. Available from: http://www.ncbi.nlm.nih.gov/pubmed/ 11146708. http://doi.org/10.1001/archinte.161.1.121

23. Norman DC. Fever in the elderly. Clin Infect Dis. 2000;31(1):148-51. Available from: http://www.ncbi.nlm.nih.gov/pubmed/10913413. http://doi.org/10.1086/313896

24. Simon H. Hyperthermia. Curr Concepts. 1993;7:483-7. 